\title{
A genetic screen identifies the Triple $T$ complex required for DNA damage signaling and ATM and ATR stability
}

\author{
Kristen E. Hurov, Cecilia Cotta-Ramusino, and Stephen J. Elledge ${ }^{1}$ \\ Howard Hughes Medical Institute and Department of Genetics, Harvard Medical School, Division of Genetics, \\ Brigham and Women's Hospital, Boston, Massachusetts 02115, USA
}

\begin{abstract}
In response to DNA damage, cells activate a complex signal transduction network called the DNA damage response (DDR). To enhance our current understanding of the DDR network, we performed a genome-wide RNAi screen to identify genes required for resistance to ionizing radiation (IR). Along with a number of known DDR genes, we discovered a large set of novel genes whose depletion leads to cellular sensitivity to IR. Here we describe TTI1 (Tel two-interacting protein 1) and TTI2 as highly conserved regulators of the DDR in mammals. TTI1 and TTI2 protect cells from spontaneous DNA damage, and are required for the establishment of the intra-S and G2/M checkpoints. TTI1 and TTI2 exist in multiple complexes, including a 2-MDa complex with TEL2 (telomere maintenance 2), called the Triple T complex, and phosphoinositide-3-kinase-related protein kinases (PIKKs) such as ataxia telangiectasia-mutated (ATM). The components of the TTT complex are mutually dependent on each other, and act as critical regulators of PIKK abundance and checkpoint signaling.
\end{abstract}

[Keywords: TTI1; TEL2; TTI2; PIKK; TTT complex; IR sensitivity]

Supplemental material is available at http://www.genesdev.org.

Received April 5, 2010; revised version accepted July 22, 2010.

Organisms experience significant amounts of DNA damage, which threatens their survival on a daily basis. To address this damage and optimize survival, cells evolved the DNA damage response (DDR), a complex signal transduction network that activates transcription and DNA repair, and coordinates cell cycle transitions in order to maintain genomic stability. The central regulators of the DDR are ataxia telangiectasia-mutated (ATM) and ataxiatelangiectasia and Rad3-related (ATR), two members of the mammalian phosphoinositide-3-kinase-related protein kinase (PIKK) family. ATM is critical for the cellular response to DNA double-strand breaks (DSBs), and mutations in ATM lead to the neurodegenerative and cancer predisposition disease ataxia telangiectasia (Lavin 2008). ATR is activated by replication stress, and is an essential gene in budding yeast and mice. In addition, a hypomorphic mutation in ATR results in Seckel syndrome, a developmental disorder characterized by growth retardation and microcephaly (Cimprich and Cortez 2008). In mammals, there are four additional members of the PIKK family that have diverse functions. They include DNA-PKcs (the DNA-dependent protein kinase catalytic subunit), which is crucial for DNA repair of DSBs by nonhomologous

${ }^{1}$ Corresponding author.

E-MAIL selledge@genetics.med.harvard.edu; FAX (617) 525-4500.

Article is online at http://www.genesdev.org/cgi/doi/10.1101/gad.1934210. end-joining, and SMG1 (suppressor with morphological effect on genitalia 1), which regulates nonsense-mediated decay of aberrant mRNA. In addition, this family includes mTOR (mammalian target of rapamycin), which controls cell growth in response to environmental cues, mitogenic signals, and nutrient availability, and TRRAP (the catalytically inactive transformation/transcription domainassociated protein), a regulator of gene expression via its association with histone acetyltransferase complexes.

Recently, a common interacting protein between all six of the mammalian PIKKs that affects their stabilities was identified as TEL2 (telomere maintenance 2) (Takai et al. 2007). TEL2 was originally identified in Saccharomyces cerevisiae in a screen for mutants that altered telomere length (Lustig and Petes 1986). It was subsequently identified in Caenorhabditis elegans in a screen for maternal-effect viable mutants, and as a gene important for biological rhythms and life span and named CLK2 (Hekimi et al. 1995; Lakowski and Hekimi 1996). Later, it became apparent that a gene required for radiation sensitivity and the DNA damage checkpoint, RAD-5, was allelic with CLK-2 (Ahmed et al. 2001). The TEL2/ CLK2 orthologs in C. elegans and the budding yeast S. cerevisiae are important regulators of telomere length (Runge and Zakian 1996; Kota and Runge 1999; Benard et al. 2001; Lim et al. 2001). In mammals and the fission yeast Schizosaccharomyces pombe, TEL2/CLK2 has been 
Hurov et al.

heavily implicated in the ATR signaling pathway and the S-phase checkpoint (Collis et al. 2007, 2008; Shikata et al. 2007; Danielsen et al. 2009). The connection between TEL2 and the PIKK family helps explain the pleiotrophic nature of the phenotypes of TEL2 mutants in different organisms. However, it is not known whether TEL2 works alone or is a part of a larger machine involved in PIKK regulation. The determination of the precise composition of the TEL2 complex will be critical to the elucidation of its mechanism of action in promoting PIKK activity.

In this study, we report the results of a genome-wide RNAi screen for genes required for IR resistance in which we identify a novel regulator of the DDR, TTI1 (Tel twointeracting protein 1), which plays a critical role in DNA damage resistance and the establishment of cell cycle checkpoints. We find that TTI1 and its associated protein, TTI2 (C8ORF41), are required for DDR signaling through control of the protein levels of ATM, ATR, and a group of related PIKKs, suggesting a connection to TEL2. TTI1 and TTI2 associate physically with TEL2 to form a conserved trimeric complex called the Triple $\mathrm{T}$ complex. Interestingly, TTI1 and TTI2 are also required for maintaining the protein levels of TEL2. However, expression of exogenous TEL2 cannot restore DNA damage resistance in TTI1depleted cells, indicating a specific role for TTI1 in the DDR. We propose that the TTT complex is a master regulator of PIKK abundance and DDR signaling.

\section{Results}

\section{A genome-wide RNAi screen for genes required for $I R$ resistance}

We recently developed retroviral barcoded, microRNAbased shRNA libraries targeting the entire human genome that can be used in complex pools of shRNAs that can be deconvoluted by microarray technology (Paddison et al. 2004; Silva et al. 2005, 2008; Schlabach et al. 2008). In this study, we performed a genome-wide loss-of-function screen to identify genes whose inhibition leads to sensitivity to ionizing radiation (IR) in U2OS cells (Fig. 1A). We screened U2OS cells with 74,905 retroviral shRNAs targeting 32,293 unique human transcripts (including 19,542 RefSeq transcripts) in six pools of $\sim 13,000$ shRNAs per pool and a "focused" sublibrary consisting

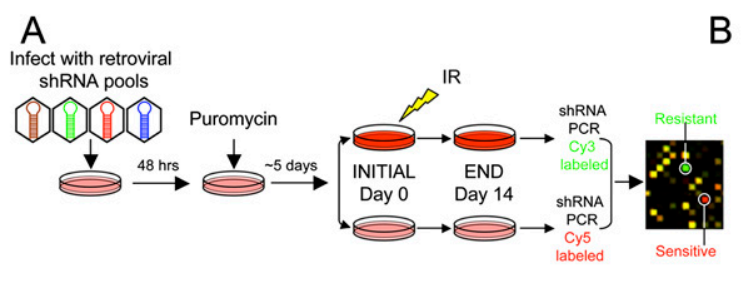

B

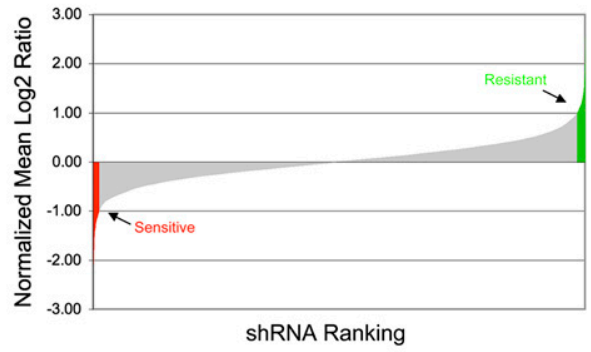

C

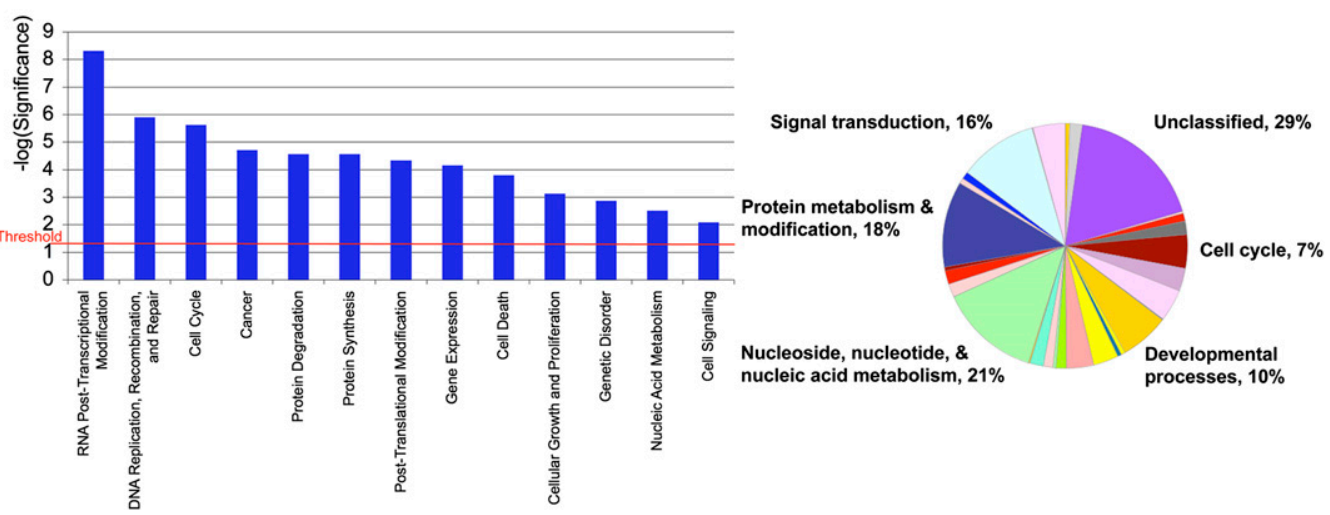

Figure 1. A genome-wide RNAi screen to search for novel DDR genes. (A) Schematic of the pool-based shRNA screen for regulators of the DNA DSB response in mammalian cells. shRNA pools were deconvoluted using microarray hybridization. $(B)$ The screen behavior of a representative shRNA pool of 12,965 shRNAs. shRNAs are graphed based on their mean-normalized log2 Cy5/Cy3 ratio, with a ratio of less than -1 indicating a decrease in the relative abundance of the shRNA greater than twofold, and a ratio of $>1$ representing an increase in the relative abundance of the shRNA greater than twofold. The population of shRNAs causing IR sensitivity is shaded in red, and IR resistance is shaded in green. $(C, D)$ Gene ontology analysis of the candidate genes required for IR resistance. $(C)$ Significance refers to the $-\log (P$-value $)$ determined by the right-tailed Fisher's exact test. Threshold is at $1.25=-\log (P=0.05)$. The analysis includes 760 genes from Supplemental Table S1 whose gene symbols were identified by Ingenuity's Knowledge Base. $(D)$ The candidate genes required for IR resistance were classified into several biological processes by the PANTHER program. The analysis includes 760 genes from Supplemental Table S1 whose Entrez Gene IDs were identified by PANTHER. 
of 8000 shRNAs against kinases, phosphatases, ubiquitin ligases, and genes implicated in cancer. The shRNA pools in MSCV-PM were introduced into U2OS cells at a multiplicity of infection (MOI) of 1 following a protocol described previously (Schlabach et al. 2008; Luo et al. 2009; Wang et al. 2009). The cells were puromycinselected, treated with 5 Gy IR (or left untreated), and propagated for $\sim 2 \mathrm{wk}$, and the end samples were collected for processing for pool deconvolution. Using microarray hybridization, we monitored the change in relative abundance of each shRNA from the untreated cells to the IRtreated cells. We identified both a set of shRNAs that dropped out of the IR-treated cells and a set that was enriched in the IR-treated cells (Fig. 1B). Actual screen data are plotted as a normalized $\log 2$ (Cy5/Cy3) ratio. Our screen identified 850 shRNAs corresponding to 813 genes that are required for IR resistance in U2OS cells (Supplemental Table S1; see the Materials and Methods for the criteria used to select hits). The candidate IR-enriched shRNAs are listed in Supplemental Table S2.

To better understand our IR sensitivity data set, we performed a bioinformatics analysis of the genes targeted by the shRNAs. We used Ingenuity Pathway Analysis (Ingenuity Systems, http://www.ingenuity.com) to determine the significance of certain functional categories in our list by determining their enrichment relative to the total number of genes in their respective categories (Fig. 1C). The DNA replication, recombination, and repair category and the cell cycle category showed a highly significant enrichment in our data set. Enrichment was also found for genes involved in cancer, protein degradation, post-translational modifications, and cell signaling (Fig. 1C). Unexpectedly, the category that showed the most enrichment was RNA post-transcriptional modification, which includes genes involved in spliceosome assembly, RNA splicing, polyadenylation of mRNA, and processing of mRNA and rRNA. This functional group was also highly enriched in the ATM/ATR substrates identified in our proteomics screen (Matsuoka et al. 2007). We also annotated the list of candidate IR sensitivity genes in the gene ontology format. Using PANTHER, we found many biological processes to be enriched, including nucleic acid metabolism, protein modification, signal transduction, and cell cycle (Fig. 1D; Thomas et al. 2003; Mi et al. 2007). Importantly, we found a significant number of genes that have remained unclassified, indicating the potential of this screen to uncover novel DDR genes.

\section{$D D R$ and cell cycle genes uncovered in the screen}

Many genes with a known link to the DDR, as well as genes that function in DNA replication and cell division, were identified in the screen. We found a subset of genes for which multiple independent shRNAs were depleted from the IR-treated population greater than twofold that included several known DDR regulators as well as genes not previously linked to the DDR (Fig. 2A; Supplemental Table S1 [all multiple shRNA hits are highlighted in pink]; see below). Our screen scored four shRNAs against the ATM kinase, which is central to the entire DDR. In addition, four shRNAs scored against DNA-PKcs, a kinase involved in nonhomologous end-joining DNA repair. Also, UBC13 and NBA1/MERIT40 both scored with multiple shRNAs. UBC13 and NBA1 are both required for recruitment of BRCA1 to sites of DNA damage. NBA1 was identified in a preliminary version of this screen (Wang et al. 2009). We used the Ingenuity pathway analysis software to create a network of genes known to be involved in the DDR, DNA replication, or cell cycle progression (Fig. 2B). In Figure 2B, the genes marked in red indicate that at least one shRNA against this gene scored in the screen (Supplemental Table S3; see the Materials and Methods for a description of how this list was generated). To validate shRNAs using an independent assay, shRNAs were tested using the multicolor competition assay (MCA) (Smogorzewska et al. 2007). In brief, uncolored U2OS cells expressing a control shRNA were mixed in a 50:50 ratio with U2OS cells expressing dsRed and the shRNA of interest, and were either left untreated or treated with IR. Eight days after IR, the percentage of dsRed-expressing cells was measured by FACS, and IR-treated cells were normalized to untreated cells to correct for proliferation differences. We used this viability assay to validate several genes that have been linked previously to DNA repair, DNA replication, or cell cycle (Fig. 2C). A full list of validated shRNAs using MCA is shown in Supplemental Table S4, and, overall, 115 out of 292 tested shRNAs validated for a rate of $\sim 40 \%$. As mentioned above, two of the strongest hits were ATM and DNA-PK, and both validated with multiple shRNAs in our independent viability assay. In addition, the DDR kinase ATR, UBC13, and NBA1 validated using MCA. We also identified C9ORF80, which was characterized recently using proteomics as a member of a trimeric complex containing SSB1/2 and INTS3 that is important for the DDR (Huang et al. 2009; Li et al. 2009; Skaar et al. 2009). Other validated hits include Topoisomerase 1 (TOP1), the replication licensing factor MCM6, and NIPBL, a gene involved in sister chromatid cohesion and mutated in Cornelia de Lange syndrome (Tonkin et al. 2004). We also found genes whose yeast orthologs have been shown to be required for DNA damage resistance, including RBBP4/ CAF-1 p48 subunit/RBAP48 (S. cerevisiae MSI1/CAC3) and RNF20 (S. cerevisiae BRE1A) (Kaufman et al. 1997; Giannattasio et al. 2005; Linger and Tyler 2005).

\section{TTI1 is required for DNA damage resistance}

Our screen identified a previously uncharacterized ORF, KIAA0406 (Entrez GeneID: 9675; accession no.: NM_014657), which we will refer to as TTI1 for reasons described below. TTI1 is highly conserved throughout evolution, with orthologs in mice, chickens, flies, frogs, fish, plants, and yeast (Supplemental Fig. S1). We identified one shRNA targeting TTI1 that scored greater than twofold reduction in two independent microarray hybridizations (Fig. 3A; see the Materials and Methods for details on hybridizations). To validate that TTI1 depletion leads to increased IR sensitivity, we used the MCA described above with multiple shRNAs and siRNAs (Fig. 
Hurov et al.

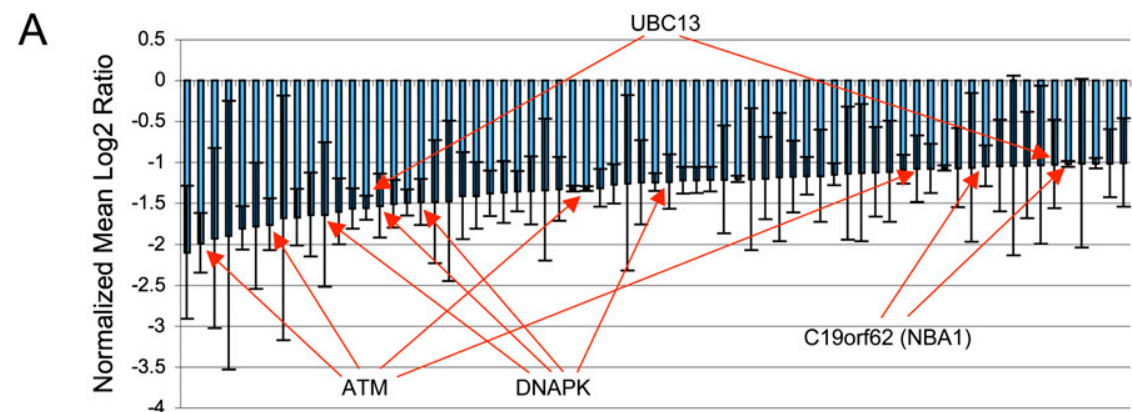

B

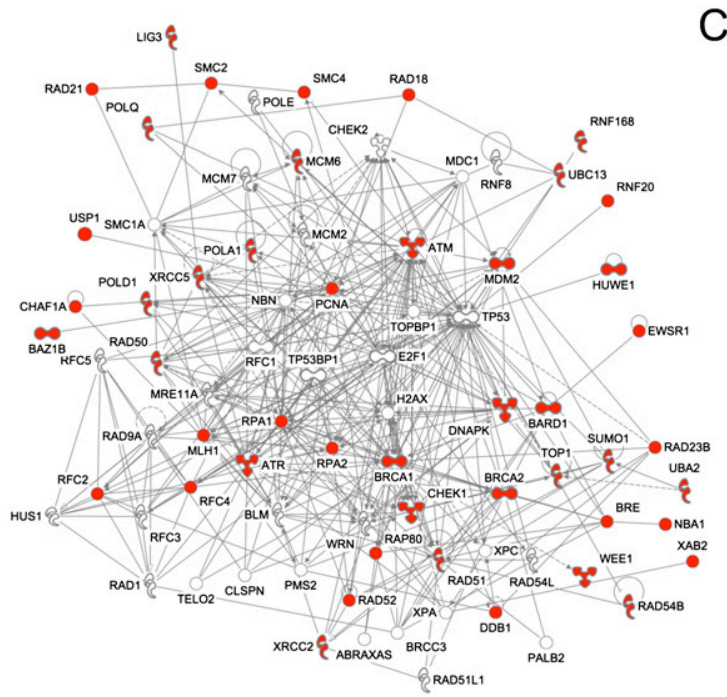

C

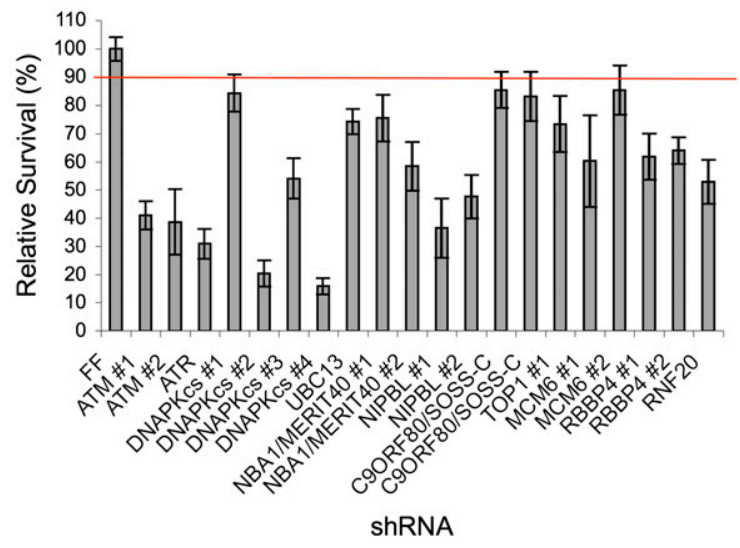

Figure 2. Many known DDR, DNA replication, and cell cycle genes scored in the IR sensitivity screen. $(A)$ Screen data of genes that scored with multiple shRNAs, which included known DDR genes, ATM, DNAPK, UBC13, and NBA1. In addition, multiple genes not previously linked to the DDR scored with multiple shRNAs. These data are from the IR screen in U2OS cells treated with 5 Gy and hybridized UNTREATED-END versus IR-END. $(B)$ Ingenuity pathway analysis of genes implicated previously in the DDR, DNA replication, and the cell cycle. Genes labeled in red scored in the IR sensitivity screen (data from multiple screen conditions included) (see the Materials and Methods; Supplemental Table S3). The cross represents a kinase, the squiggle represents an enzyme, the barbell represents a transcription regulator, and the circle represents a protein not classified into one the these three groups. $(C)$ Validation of known DDR, DNA replication, and cell cycle genes using an independent viability assay. MCA was performed using U2OS cells expressing dsRed and the individual shRNAs indicated. Cells were mixed equally with uncolored U2OS cells expressing a control FF shRNA, treated with $3 \mathrm{~Gy}$ of IR, and incubated for $7 \mathrm{~d}$, and the relative cell number was determined by FACS. IR-treated samples were normalized to untreated cells and graphed as "percent relative survival." V2HS numbers (Open Biosystems) for these shRNAs are listed in Supplemental Table S6.

3B,D). The TTI1 shRNA that scored in the screen (\#3) depleted TTI1 mRNA (Fig. 3C) and led to decreased cell viability in response to IR, mitomycin $\mathrm{C}(\mathrm{MMC})$, and camptothecin (CPT) (Fig. 3B,F). We further tested two additional shRNAs and four siRNAs that target distinct regions of the TTI1 sequence (Fig. 3B,D). Both shRNAs and three of four siRNAs gave DNA damage sensitivity to IR, ultraviolet (UV), or both, which correlated with the degree of TTI1 protein depletion (Fig. 3B-E). An additional shRNA, TTI1 \#4, also led to strong TTI1 depletion and DNA damage sensitivity (Fig. 7D,E, below). The effect of ATM depletion is shown in each case for comparison (Fig. 3B,D; Supplemental Fig. S4). Furthermore, when we reintroduced a TTIl cDNA lacking the shRNA \#3 target site, which exists in the $3^{\prime}$ untranslated region (UTR) of the endogenous gene, into cells treated with TTI1 shRNA \#3, the shRNA-resistant cDNA re- versed the DNA damage sensitivity of the TTI1 shRNA (Fig. 3F). To further confirm our results using the MCA assay, we performed colony survival assays and found that TTI1 depletion led to significant IR sensitivity at multiple doses of damage (Supplemental Fig. S3). Thus, TTI1 is required for resistance to DNA damage.

\section{TTI1 controls the G2/M and intra-S-phase DNA damage checkpoints}

To further explore the role of TTIl in the DDR, we monitored the ability of cells depleted of TTIl to arrest the cell cycle in S and G2 phases in response to IR. To test G2 arrest, TTI1-depleted cells were treated with 10 Gy IR, and, after $1 \mathrm{~h}$, were treated with nocodozole for $17 \mathrm{~h}$ to allow accumulation in mitosis, measured by phosphoS10 histone H3 staining. TTI1-depleted cells were unable 

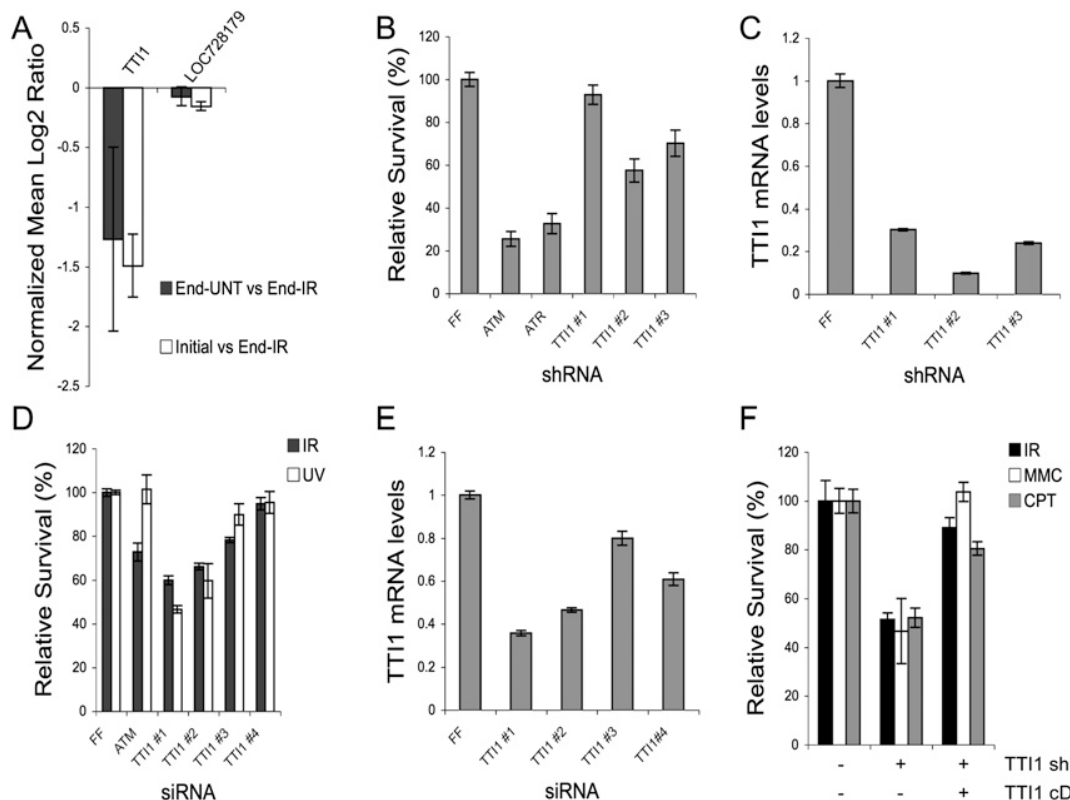

F

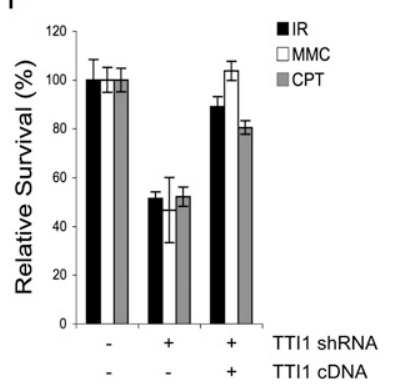

Figure 3. KIAA0406/TTI1 is required for DNA damage resistance. (A) Identification of KIAA0406/TTI1 as a gene required for IR resistance. shRNAs were graphed based on their mean-normalized $\log 2 \mathrm{Cy} 5 / \mathrm{Cy} 3$ ratio. An unrelated shRNA that was considered unchanged is shown for comparison. $(B)$ Validation of the TTI1 shRNA that scored in the screen (\#3) and two additional TTI1 shRNAs. Cell viability was monitored using MCA as described in Figure 2C, and was normalized to the FF control virus. Viability in response to 3 Gy of IR was monitored. Error bars represent the standard deviation of three replicates. (C) Quantitative RTPCR was used to measure the efficiency of shRNA depletion of TTI1 mRNA relative to $\beta$-actin as described in the Materials and Methods. Error bars represent the standard deviation of four replicates. $(D)$ siRNAs that target distinct regions of the TTI1 sequence also lead to increased IR sensitivity. Four individual siRNAs from Dharmacon targeting TTI1 were tested (Supplemental Table

S7). Cell viability using the MCA assay was monitored as in Figure 2C. Viability in response to 3 Gy of IR or $5 \mathrm{~J} / \mathrm{m} 2 \mathrm{UV}$ was monitored. Error bars represent the standard deviation of three replicates. (E) Quantitative RT-PCR was used to measure the efficiency of siRNA depletion of TTI1 mRNA as in C. (F) Expression of a shRNA-resistant TTI1 cDNA restores DNA damage resistance. U2OS cells stably expressing MSCV-HA-Flag-empty vector or MSCV-HA-Flag-TTIl were infected with retroviruses that express either FF control shRNA or TTI1 shRNA \#3, and, after 2 d, were mixed with control cells for MCA. Viability in response to 3 Gy of IR, $75 \mathrm{nM}$ MMC, or $5 \mathrm{nM}$ CPT was monitored. Error bars represent the standard deviation of three replicates.

to efficiently arrest in G2 in response to IR (Fig. 4A; Supplemental Fig. S5), suggesting that TTI1 is required for the G2/M checkpoint. To test the integrity of the intra-S-phase checkpoint, we measured the levels of radio-resistant DNA synthesis. At 45, 90, and $180 \mathrm{~min}$ following IR treatment, control or TTI1 shRNA-depleted cells were pulse-labeled with ${ }^{3} \mathrm{H}$-thymidine for $20 \mathrm{~min}$ and incorporation of radioactive thymidine was monitored. IR-treated control U2OS cells displayed $\sim 40 \%$ DNA synthesis at the 180-min time point compared with untreated cells, whereas cells depleted of ATM or TTI1 displayed $\sim 80 \%-90 \%$ DNA synthesis (Fig. 4B). Thus, TTI1 depletion leads to a defective intra-S-phase checkpoint on the order of cells depleted of ATM, the central regulator of the DDR. Therefore, TTI1 is critical for the efficient inhibition of DNA replication in response to DNA damage.

\section{TTI1 depletion leads to defective DDR signaling}

Since TTIl shRNA-treated cells displayed defective DNA damage-induced cell cycle arrest, we examined DDR signaling itself. We found that IR-induced phosphorylation of several targets of ATM-including CHK2, NBS1, SMC1, and KAP1-was reduced in TTI1-deleted cells (Fig. 5A). In addition, we found that phosphorylation of CHK1 on Ser 317 was very low in TTI1-depleted cells treated with IR or UV compared with a control shRNA (Supplemental Fig. S6). These defects correlate with a strong reduction in ATM and ATR protein levels (Fig. 5A; Supplemental Fig. S6). This finding helps to explain the IR sensitivity phenotype and checkpoint defects seen in TTI1-depleted cells.

TTI1 is required to maintain PIKK protein abundance

Since we observed a profound effect on ATM and ATR protein levels in cells expressing TTIl shRNAs, we investigated the possibility that TTIl might also control other PIKKs. In U2OS cells stably expressing a TTI1 shRNA, the levels of the other PIKK family members-including DNA-PKcs, mTOR, SMG1, and TRRAP-were also reduced (Fig. 5B). We did not see an effect on the levels of PI3K subunits $\mathrm{p} 110 \alpha$ or $\mathrm{p} 85$ (data not shown). Two independent shRNAs targeting TTI1 were used for this analysis, with shRNA \#2 producing greater depletion of TTI1 and a correspondingly stronger effect on PIKK levels. These data suggest that TTI1 may function in other cellular processes in addition to the DDR. Consistent with this, we found that signaling downstream from mTORC2, one of the mTOR-containing complexes, was defective in TTI1-depleted cells (Supplemental Fig. S8; Hresko and Mueckler 2005; Sarbassov et al. 2005).

To investigate the mechanism by which TTIl controls the levels of the PIKKs, we monitored the effect of TTI1 depletion on PIKK transcripts. TTI1 depletion does not have a significant effect on PIKK mRNA levels at early time points, where we already see strong reduction in PIKK protein (Supplemental Fig. S7A,B). However, TTI1depleted cell lines carried under puromycin selection for several days did display a decrease in transcript levels 
A
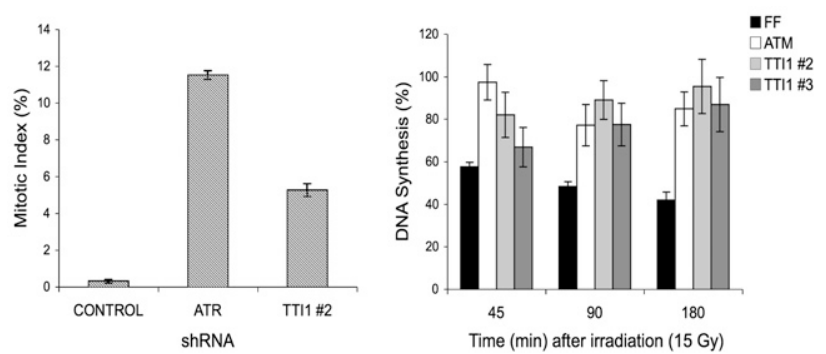

Figure 4. Depletion of TTIl leads to cell cycle checkpoint defects. (A) U2OS cells depleted of TTI1 have a G2/M cell cycle checkpoint defect. U2OS cells stably expressing control, ATR, or TTI1 shRNAs were treated with 10 Gy of IR or left untreated. After $1 \mathrm{~h}$, nocodozole was added, and cells were incubated for an additional $17 \mathrm{~h}$. Cells were fixed and stained for phospho-S10 histone H3. The mean percentage of phospho-S10 histone H3positive cells (mitotic index) is plotted. The error bars represent standard deviation across three technical replicates. $(B)$ U2OS cells depleted of TTI1 display an intra-S-phase cell cycle checkpoint defect. U2OS cells stably expressing either control, ATM, or TTIl shRNAs were labeled with ${ }^{14} \mathrm{C}$-thymidine for 24 $\mathrm{h}$, followed by $24 \mathrm{~h}$ in medium containing no label. Cells were treated with 15 Gy of IR for 45, 90, or $180 \mathrm{~min}$; pulse-labeled with ${ }^{3} \mathrm{H}$-thymidine for $20 \mathrm{~min}$; and harvested; the DNA was fixed onto filters; and ${ }^{14} \mathrm{C}$ and ${ }^{3} \mathrm{H}$ incorporation was measured and normalized to untreated cells. Error bars represent the standard deviation across three technical replicates.

(data not shown). These results suggest that the initial decrease in PIKK protein levels occurs post-transcriptionally in the absence of TTI1.

\section{TTI1 interacts with TEL2 and other PIKKs in mammals}

The phenotype of TTI1-depleted cells suggests that TTI1 might play a direct role in PIKK stability by associating with PIKKs, reminiscent of the role proposed for TEL2 (Collis et al. 2007; Takai et al. 2007). Immunoprecipitation of Flag-HA-tagged TTI1 revealed the presence of the PIKKs ATM, ATR, DNA-PKcs, SMG1, and mTOR (Fig. 5C). Endogenous ATM and ATR were also present in immunoprecipitates of endogenous TTI1 (Fig. 5D,E). In addition, to further confirm the association of TTI1 with PIKKs, reciprocal coimmunoprecipitatons were performed, and both endogenous ATM and Flag-tagged ATM were able to immunoprecipitate endogenous TTI1 (Fig. 5F; Supplemental Fig. S9). Interestingly, it appears that, following IR treatment, several PIKKs show a small reduction in their interaction with TTI1-in particular, those that are activated by DNA damage, ATM, ATR, and DNA-PKcs (Fig. 5C,E).

The effect on PIKK abundance and the physical association with PIKKs strongly suggested a role in the TEL2 pathway. Interestingly, a physical link between PIKKs and fungal TTI1 had been detected previously through mass spectrometry analysis of Tor $1 / 2$ complexes. S. pombe SPCC622.13c was found to associate with Tor1/Tor2 and, subsequently, Tel2/SPAC458.03 proteins, and was named Ttil (Hayashi et al. 2007). In addition, a second protein, SPBC1604.17c/Tti2, was also identified as a Tel2-associated protein, and is conserved in humans (C8ORF41; Entrez GeneID: 80185) and other species (Supplemental Fig. S2). Although S. pombe Ttil and Tti2 were found in Tor $1 / 2$ and Tel2 immunoprecipitates, their functional relationship to Tel2 and DNA damage
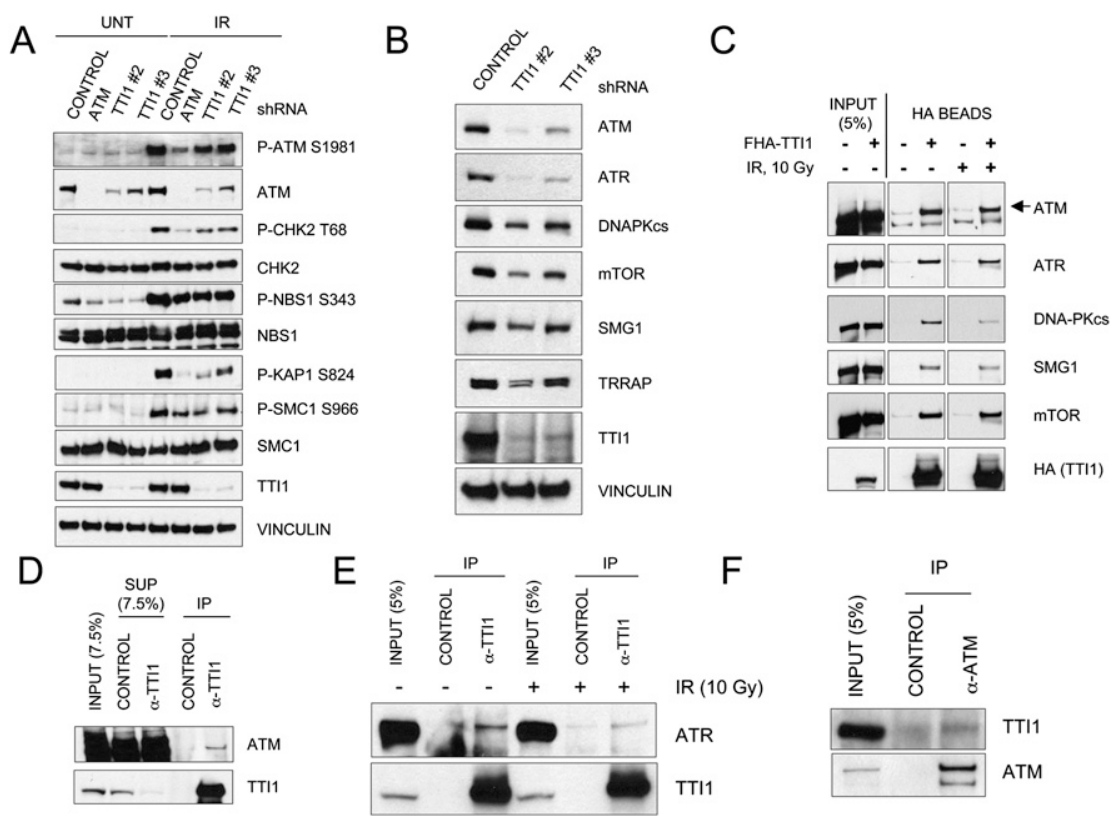

Figure 5. TTI1 interacts physically with PIKKs to regulate their abundance. $(A)$ TTI1 depletion leads to defective DDR signaling. U2OS cells stably expressing a control, ATM, or two different TTIl shRNAs were treated with $10 \mathrm{~Gy}$ of IR, followed by $4 \mathrm{~h}$ of incubation prior to harvesting. Protein lysates were immunoblotted using the indicated antibodies. $(B)$ Protein from U2OS cells stably expressing a control or two different TTIl shRNAs was immunoblotted using TTI1, ATM, ATR, DNAPK, mTOR, SMG1, TRRAP, or VINCULIN (loading control) antibodies. (C) $293 \mathrm{~T}$ cells were transiently transfected with Flag-HA-TTI1 or an empty vector for $36 \mathrm{~h}$, and were either left untreated or treated with 10 Gy of IR for $4 \mathrm{~h}$. Proteins immunoprecipitated with HA antibodies were immunoblotted with the indicated antisera. All lanes were run on the same gel and have the same immunoblot exposure. $(D)$ An antibody generated against the C terminus of TTI1 immunoprecipitated endogenous TTI1 and ATM. Normal rabbit IgG was used for a control immunoprecipitation. (E) An antibody against endogenous TTI1 immunoprecipitates endogenous ATR. 293T cells were left untreated or treated with 10 Gy of IR for $4 \mathrm{~h}$. (F) An antibody against endogenous ATM immunoprecipitates endogenous TTIl. 
signaling was not explored, and it is not known whether this interaction is conserved in humans. To examine the latter, Flag-HA-tagged TTI1 expressed in U2OS cells was immunoprecipitated and found to coimmunoprecipitate endogenous human TEL2 (Fig. 6A). In addition, tagged TEL2 (C-terminal Flag-HA tag) and Myc-tagged TTI1 reciprocally coimmunoprecipitated each other, and this interaction was not significantly altered in response to DNA damage (Fig. 6C; Supplemental Fig. S10). To examine endogenous protein association, we generated an antibody against a C-terminal peptide in TTI1. This antibody was capable of immunoprecipitating endogenous TTI1 and TEL2 (Fig. 6B). Immunoprecipitation of human TTI2 also coimmunoprecipitated TEL2 and TTI1 (Fig. 6D). In addition, we identified TTI1 by mass spectrometry in HA-TTI2 immunoprecipitates (data not shown).

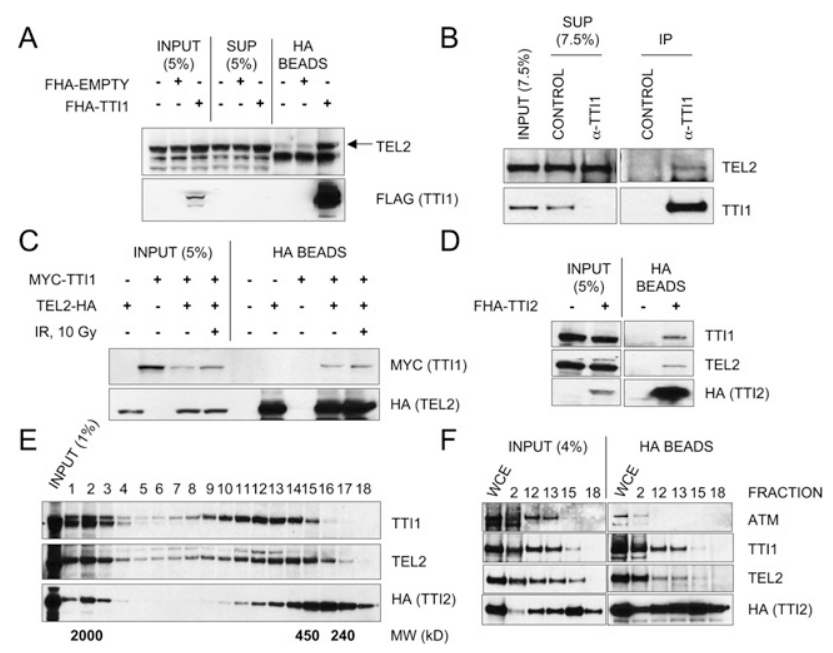

Figure 6. Human TTI1 and TTI2 associate physically with TEL2. (A) Epitope-tagged TTIl can coimmunoprecipitate endogenous TEL2. Flag-HA-TTI1 was transiently transfected into 293T cells, and proteins immunoprecipitated with $\mathrm{HA}$ antibody-conjugated beads were separated by SDS-PAGE, transferred to PVDF, and immunoblotted with anti-TEL2 antisera or anti-Flag-HRP. (B) An antibody generated against the C terminus of TTI1 coimmunoprecipitated endogenous TTI1 and TEL2. Normal rabbit IgG was used for a control immunoprecipitation. $(C)$ TEL2 can coimmunoprecipitate TTI1 independently of IR treatment. MYC-TTI1 (N-terminal MYC tag) and/or TEL2-FHA (C-terminal Flag-HA tag) were transiently transfected into $293 \mathrm{~T}$ cells, and proteins were immunoprecipitated with HA antibodies and immunoblotted with anti-MYC or anti-HA antibodies. Thirty-six hours after transfection, cells were either left untreated or treated with $10 \mathrm{~Gy}$ of IR for $4 \mathrm{~h}$ prior to harvesting. $(D)$ TTI2 interacts with both TTI1 and TEL2. FHA-TTI2 (N-terminal Flag-HA tag) was transiently transfected into $293 \mathrm{~T}$ cells, and HA immunoprecipitates were immunoblotted with anti-TEL2 and anti-TTI1 antibodies. $(E)$ TTI1, TEL2, and TTI2 cofractionate in a large-molecular-weight complex on Superose 6. 293 TRex cells containing a doxycyclineinducible Flag-HA-TTI2 were treated with $2 \mathrm{ug} / \mathrm{mL}$ doxycycline for $24 \mathrm{~h}$ prior to preparation of whole-cell extract. The molecular weight standards and the corresponding fractions they eluted off of the Superose 6 column are listed in Supplemental Table S5. (F) Fractions from extracts run on a Superose 6 column (shown in E) were used as input for immunoprecipitation with HA antibodyconjugated beads.
To further confirm that TTI1, TEL2, and TTI2 all interact together as a complex, we examined whether these proteins cofractionate on a sizing column. We found that all three proteins cofractionate on a Superose 6 column in a large complex of molecular weight $2000 \mathrm{KDa}$ (Fig. 6E). In addition, TTI1 and TEL2 peaked in a smaller complex (>450 kD, fractions 12 and 13), while TTI2 was also present in these fractions. Protein molecular weight standards and where they fractionate on the Superose 6 column are listed in Supplemental Table S5. The fractionation of TTI1, TEL2, and TTI2 did not significantly change if the cells were treated with IR (data not shown). To determine whether the TTT complex was intact in the peak fractions, we used fractions $2,12,13,15$, and 18 as input material for immunoprecipitation with HA antibody-conjugated beads, and found that TEL2 and TTI1 interacted with HA-TTI2 in fraction 2 (Fig. 6F). Despite significantly less TTI2 in fraction 2, HA-TTI2 brought down more TEL2 in fraction 2 than in fraction 12. This suggests that TEL2 in fraction 12 is bound much more weakly than in fraction 2, but the TTI1-TTI2 interaction remains strong in fraction 12 . Importantly, ATM coimmunoprecipitated only with the TTT complex in fraction 2 , suggesting that this fraction contains the active complex, and that, perhaps, PIKKs help it assemble. Altogether, these data suggest that the entire TTT complex is conserved throughout eukaryotic evolution.

\section{All three TTT complex components are required for DNA damage resistance}

To investigate more completely the involvement of the individual TTT complex subunits in the DDR, we assayed viability in response to IR and MMC in cells stably expressing TTI1, TEL2, or TTI2 shRNAs. All shRNAs led to efficient depletion of these components, as monitored by immunoblotting (TTI1 and TEL2) or RT-PCR (TTI2) (Fig. 7E; Supplemental Fig. S14). Three shRNAs against TEL2 led to decreased survival in response to IR and MMC, with TEL2 \#1 giving the strongest phenotype (and most efficient depletion) (Fig. 7D,E, left panel). Also, three shRNAs against TTI2 led to decreased survival in response to IR and $M M C$, with TTI2 \#2 having the strongest effect (Fig. 7D,E, right panel). The phenotypes of ATM, ATR, and TTI1 shRNAs are shown for comparison. Furthermore, TEL2 and TTI2 shRNAs also led to decreased levels of ATM and ATR, consistent with the decreased viability results (Fig. 7E). MCA assays done with cells depleted of TTT complex subunits using siRNAs are provided for comparison (Supplemental Fig. S13B,C). Thus, overall, our data support a critical role for the entire TTT complex in the DDR.

\section{TTT complex components depend on each other for their stability}

While all three members of the TTT complex associate together, the extent to which each subunit was required was unclear. To address this, we examined the relationship between TTI1 and TEL2. U2OS cells expressing shRNAs against TTI1 showed reduced levels of TEL2 
Hurov et al.

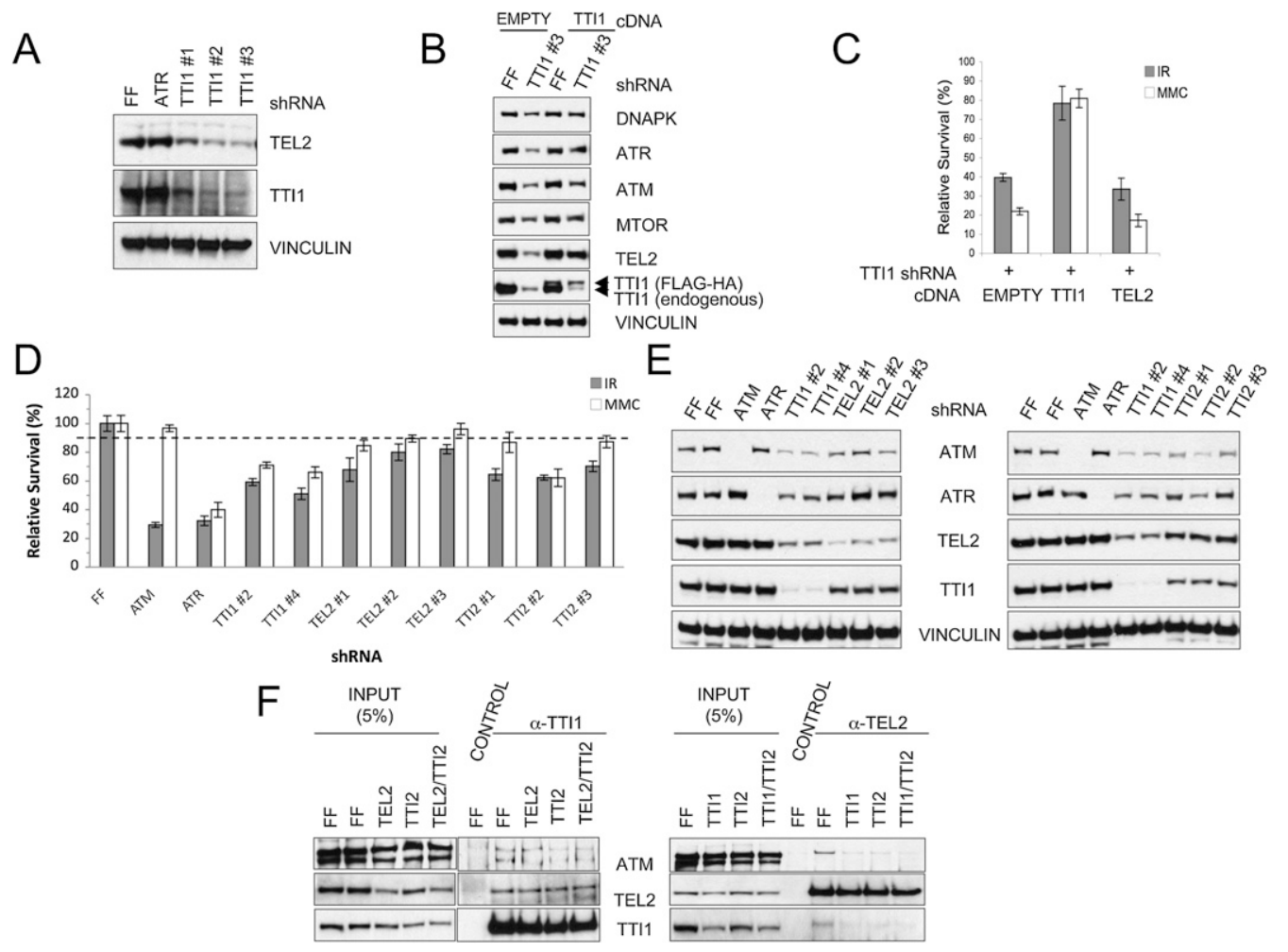

Figure 7. TTI1 and TTI2 are required for maintaining TEL2 protein levels, and are critical components of the TTT complex. (A) TTI1 is required to maintain TEL2 protein levels. Whole-cell extracts from U2OS cells stably expressing control, ATR, or TTI1 shRNAs were immunoblotted with TEL2, TTI1, or VINCULIN antisera. (B) Expression of an shRNA-resistant TTI1 cDNA can restore TEL2 and PIKK protein levels. U2OS cells stably expressing a control (FF) or TTI1 shRNA \#3 (targeting the 3'UTR of endogenous TTI1) were infected with an empty vector or Flag-HA-TTI1 for $2 \mathrm{~d}$. Whole-cell extracts were immunoblotted with the indicated antisera. $(C)$ Overexpression of TEL2 does not restore IR resistance to TTI1-depleted cells. U2OS cells stably expressing TTI1 shRNA \#3 were infected with retroviruses expressing MSCV-HA-Flag-empty, MSCV-HA-Flag-TTI1, or MSCV-TEL2-HA-Flag, and, after $2 \mathrm{~d}$, were mixed with control cells for MCA. Viability in response to $3 \mathrm{~Gy}$ of IR or $75 \mathrm{nM}$ MMC was monitored. $(D)$ Each subunit of the TTT complex is required for DNA damage resistance. MCA was performed using U2OS cells expressing dsRed, and the individual shRNAs are indicated as in Figure 2C. Viability in response to 3 Gy of IR or $75 \mathrm{nM}$ MMC was monitored. shRNA sequences are listed in Supplemental Table S6. (E) Knockdown of TTT subunits affects ATM and ATR levels and levels of the other TTT subunits. Immunoblots corresponding to the viability assays shown in $D$. The lysates from cells expressing FF, ATM, ATR, TTI1 \#1, and TTI1 \#2 shRNAs are the same in both panels to allow for comparison between the effects of TEL2 and TTI2 depletion. (F) TTI1 is critical for interaction of the TTT complex with ATM. U2OS cells were transfected with siRNA duplexes and incubated for $72 \mathrm{~h}$ prior to harvesting for preparation of whole-cell extracts. Immunoprecipitations were performed using control, TTI1, or TEL2 (ProteinTech Group) antisera. TTI1, TEL2, and TTI2 pools of an equimolar mix of four siRNAs from Dharmacon were used (See Supplemental Table S7).

protein (Fig. 7A) but not TEL2 mRNA (Supplemental Fig. S11), suggesting an effect on protein stability. The effect on TEL2 abundance was also observed in an independent cell line (293T) (data not shown). Expression of an shRNA-resistant TTI1 cDNA restored TEL2 and PIKK levels in these cells (Fig. 7B, cf. lanes 2 and 4). Importantly, whereas overexpression of shRNA-resistant TTIl cDNA was able to restore IR resistance in TTI1-depleted cells, overexpression of TEL2 protein was not, indicating that the IR sensitivity phenotype is not simply due to decreased TEL2 protein in these cells (Fig. 7C; Supplemental Fig. S12). Thus, TEL2 alone is insufficient to provide protection to DNA damage, and this function likely requires the entire TTT complex.

We found a reciprocal dependency for TTIl abundance as depletion of TEL2 or TTI2 (C8ORF41) also decreased TTI1 levels, suggesting that these proteins are indeed in a complex and depend on each other for their stability (Fig. 7E; Supplemental Fig. S13A). TEL2 depletion did not affect TTI1 mRNA levels (Supplemental Fig. S11). However, it is clear that depletion of TEL2 or TTI2 does not decrease the levels of TTI1 to the same extent that TTI1 depletion decreases TEL2 (Fig. 7E; Supplemental Fig. S13A). In addition, TTI2 depletion decreases TTI1 levels more so than TEL2 depletion decreases TTI1 levels (Fig. 7E). Consistent with this, TTI1 and TTI2 depletion lead to stronger IR and MMC sensitivity than the strongest TEL2 shRNA (\#1) (Fig. 7D), and TTI1 leads to overall stronger sensitivity using siRNA depletion (Supplemental Fig. S13B,C).

To investigate further the role of TTI1 within the TTT complex and in maintaining PIKK abundance, we asked whether TTI1 is required for the TTT complex to interact with ATM. In cells depleted of TEL2, endogenous TTI1 is 
still able to interact with ATM as well as in the control cells (Fig. 7F, left panel). However, in cells depleted of TTI1, endogenous TEL2 is unable to coimmunoprecipitate ATM as efficiently as in control cells (Fig. 7F, right panel). In cells depleted of TTI2, less ATM comes down with both TTI1 and TEL2 antisera, and this is most likely because TTI2 depletion has a stronger effect on TTI1 than TEL2 depletion does (Fig. 7E). Thus, TTI1 is required for efficient binding of the TTT complex to the major DDR kinase, ATM, and therefore we argue that TTI1 plays a major role within the TTT complex and is a critical regulator of the DDR and likely other PIKK-regulated pathways in mammalian cells.

\section{Discussion}

We performed an unbiased genome-wide screen to find genes required to protect the cell from DNA DSBs. We identified a large number of DDR genes with known roles in DNA repair, replication, damage signaling, and nucleotide metabolism, as well as many genes not implicated previously in the DDR. Among these, we found a strong enrichment for genes in RNA metabolism. Genes involved in spliceosome assembly, RNA splicing, polyadenylation of mRNA, and processing of mRNA and rRNA were highly enriched. This is interesting due to the fact that, in previous screens for ATM and ATR substrates, a significant enrichment was also seen for these classes of proteins (Matsuoka et al. 2007; Stokes et al. 2007). Furthermore, in a screen to look for genes whose depletion causes genomic instability, Cimprich and colleagues (Paulsen et al. 2009) found a very strong enrichment for splicing factors and RNA-binding proteins, further underscoring a role for these factors in the DDR. It is possible that these proteins play roles in the DDR outside of an indirect role in splicing.

The strong enrichment observed for genes involved in known DDR processes suggests that many of the novel genes will also play a role in these processes. Among the novel genes, we found that the uncharacterized TTIl gene is required for resistance to IR as well as other genotoxic agents, including UV light, MMC, and CPT. TTI1 is absolutely required for proper DDR signaling. Our results reveal that TTI1 interacts with TEL2 and a second protein, TTI2, to form the TTT complex required to stabilize the protein levels of the PIKKs. TTI1 is required to maintain the abundance of TEL2, as depletion of TTI1 results in a decrease in TEL2 protein levels, most likely by controlling its stability. TEL2 has been implicated in the DDR, in particular in response to agents that activate the ATR pathway (Jiang et al. 2003; Collis et al. 2007, 2008). However, the DNA damage sensitivity phenotype observed with TTI1 depletion is not simply due to the decrease in TEL2 levels, since restoration of TEL2 expression cannot restore DNA damage resistance. We argue that TTI1 is a critical component of the TTT complex that is likely involved in mediating the interaction of the complex with PIKKs, since TTT complex depleted of TTI1 can no longer interact efficiently with ATM.

We have evidence to suggest that the activated PIKKs do not bind as tightly to the TTT complex. First, although it is a small effect, we show that TTI1 interacts less well with ATM, DNAPK, ATR, and SMG1 once they are activated by IR (Fig. 5C,E). Second, we observed that TTI1 does not localize to sites of DNA damage, indicating that TTT is unlikely to associate with activated ATM and ATR, which are localized to damage sites, further suggesting that ATM and ATR are released from TTI1 prior to their localization to DNA damage foci (data not shown). This is consistent with the observation of de Lange and colleagues (Takai et al. 2007) that TEL2 does not localize to sites of DNA damage. The simplest interpretation of these results is that TTT participates in proper folding of newly synthesized PIKKs. Once properly folded, TTT releases the PIKK, which is then capable of activation by the relevant signal transduction pathway. In the absence of TTT, PIKKs are poorly folded and fall subject to proteolysis, thereby reducing their levels. It is also possible that more complex relationships exist, including possible roles for TTT in recycling PIKKs from the active to the inactive state and back.

It will be important to determine whether a single subunit of the TTT complex contacts each of the structurally related PIKKs, or if different subunits primarily recognize different PIKKs. Baculovirus-produced Tel2 was reported to bind fragments of MTOR and ATM (Takai et al. 2007). It is possible that multiple components of the TTT complex can contact substrates, perhaps to create an extended folding template. A critical question to be resolved is the elucidation of the composition and assembly of the 2000-Da TTT complex. Are there additional subunits that contribute to this complex? Is this complex preformed, or is its assembly induced by the presence of newly translated PIKKs? Is the complex regulated in response to DNA damage? Now that the complex has been partially elucidated, reconstituting the entire TTT complex to allow its activity toward PIKKs to be explored biochemically becomes a possibility.

Is the TTT complex a chaperone? Currently, the evidence for this hypothesis is purely circumstantial. If the TTT complex acts as a chaperone to refold PIKKs, it might do so by recruiting a known chaperone/heat-shock protein, analogous to how Cdc37 recruits Hsp90 (Stepanova et al. 1996). Alternatively, it could perform chaperone duties itself, which would predict the need for energy consumption. Unfortunately, none of the TTT proteins contain conserved motifs that might give a clue to their molecular functions, and no ATPase motifs are discernable from the sequences of TTT proteins. Instead, both TTI1 and TTI2 appear to be largely composed of HEAT repeats, although they are highly divergent (K Hofmann, pers. comm.). HEAT repeats are generally thought to be protein-protein interaction regions, or may suggest some type of molecular scaffold function. Thus, identifying which non-PIKK proteins associate with TTT will be critical to the elucidation of its biochemical function. Other biochemical functions are possible for the TTT complex. For example, TTT could control a modification on PIKKs needed for their stability and activation. Alternatively, TTT could act to insert an essential cofactor needed for PIKK holoenzyme formation. The resolution of these issues will require a full 
elucidation of the TTT complex composition, and biochemical reconstitution of its role in PIKK regulation.

\section{Materials and methods}

A loss-of-function screen for radio-protective genes using shRNA libraries

The pool-based shRNA screen using half-hairpin barcode deconvolution was performed as described previously (Schlabach et al. 2008; Luo et al. 2009). Briefly, U2OS cells were infected with pools of retroviral shRNAs at a representation of 1000 and an MOI of $\sim 1$. The cells were treated with puromycin to remove cells that were uninfected and were treated with IR or left untreated, and an initial sample (population doubling 0) was collected. The rest of the population was propagated in triplicate for $\sim 12$ population doublings ( $14 \mathrm{~d}$ ), and then end samples were harvested for genomic DNA isolation. At each passage, a minimum representation of 1000 was maintained. For each sample (INITIAL, UNTREATED-END, or IR-END), shRNA half-hairpin barcodes were PCR-recovered from genomic DNA and labeled with Cy5 or Cy3 dyes, and labeled amplicons were hybridized competitively to a microarray containing corresponding probes. Custom microarrays with half-hairpin probe sequences were from Roche Nimblegen or Agilent. Array hybridization and scanning protocols were based on the manufacturer's instructions. The PCR primers used to amplify half-hairpin barcodes from genomic DNA samples were JH353F (5' -TAGTGAAGCCA CAGATGTA-3') and HHR2L (5' -ATGTATCAAAGAGATAGCA AGGTATTCAG-3'). shRNAs with $\log 2$ ratios (average of three replicates) $>1$ or less than -1 , which corresponds to a twofold change or greater, were considered enriched or depleted from the population, respectively. Two different competitive hybridizations were performed: untreated samples taken at the end of the screen (UNTREATED-END) versus IR-treated samples taken at the end of the screen (IR-END), and initial samples taken just after puromycin selection (INITIAL) versus IR-treated samples taken at the end of the screen (IR-END). The Focus library was used to screen a second cell line, the lung cancer cell line H460, using one dose of $2 \mathrm{~Gy}$ or $5 \mathrm{~Gy}$ of IR. In addition, the Focus library was also used to screen U2OS cells treated with multiple low doses of IR. Cells were treated with 2 Gy and then allowed to recover for $1 \mathrm{wk}$ before being treated again with $2 \mathrm{~Gy}$. A total of four 2 Gy doses of IR were given. Supplemental Table S1 reports the data from the genome-wide pools and the focus pool from U2OS cells treated with one dose of 5 Gy and competitive hybridization of UNTREATED-END versus IR-END. We used data collected from all of our IR screens for the network shown in Figure $2 \mathrm{~B}$, which is why some of these hits are not listed in Supplemental Table S1. Supplemental Table S3 lists all of the genes from Figure 2B that scored in our screens (those indicated in red), and what screen condition or hybridization they scored in.

\section{Cell culture}

U2OS osteosarcoma cells (American Type Culture Collection) were grown in McCoy's 5A medium supplemented with $10 \%$ fetal bovine serum and antibiotics. 293T and 293 TRex (Invitrogen) were cultured in DMEM supplemented with $10 \%$ fetal bovine serum and antibiotics.

\section{Antibodies}

Anti-human TTI1 antibody (YZ503-1) was affinity-purified from rabbit serum immunized with KLH-conjugated hTTI1 peptide corresponding to amino acids \#1071-1089 (SGQQNPYTTNVLQ
LLKELQ-COOH) (Yenzym Antibodies, LLC). Other antibodies use were TEL2B (a gift from T. de Lange), TELO2 (\#15975-1-AP, ProteinTech Group), ATM (\#A300-136A, Bethyl Laboratories), ATR (N-19) (\#sc-1887, Santa Cruz Biotechnology), DNA-PK (Ab2) (\#NA57, Calbiochem-EMD4Biosciences), SMG1 (\#A300-394A, Bethyl Laboratories), TRRAP (\#A301-132A, Bethyl Laboratories), mTOR (\#2972, Cell Signaling Technology), HA-Agarose (clone HA-7) (\#A2095, Sigma), C-MYC (9E10) (\#MMS-150R, Covance), VINCULIN (\#V9131, Sigma), Flag M2-HRP (\#A8592, Sigma), EZview Red Anti-Flag M2 Affinity Gel (\#F2426, Sigma), P-H3 S10 (\#06-570, Millipore), P-CHK1 S317 (\#2344, Cell Signaling Technology), CHK1 (\#sc-8408, Santa Cruz Biotechnology), P-ATM S1981 (\#200-301-400, Rockland), P-CHK2 T68 (\#2661, Cell Signaling Technology), P-NBS1 S343 (\#A300-189A, Bethyl Laboratories), NBS1 (\#A300-187A, Bethyl Laboratories), P-KAP1 S824 (\#A300-767A, Bethyl), P-SMC1 S966 (\#A300-050A), SMC1 (\#A300-055A, Bethyl Laboratories), CHK2 (generated in our laboratory [Matsuoka et al. 1998]), P-AKT S473 (\#4058, Cell Signaling Technology), AKT (\#9272, Cell Signaling Technology), PI3K P110 $\alpha$ (\#611398, BD Biosciences), and PI3K PAN-P85 (a gift from L. Cantley).

\section{Western blot analysis, immunoprecipitations,} and column fractionation

For whole-cell extracts, cells were lysed in NETN buffer $150 \mathrm{mM}$ Tris-Hcl at $\mathrm{pH} 8.0,100 \mathrm{mM} \mathrm{NaCl}, 5 \mathrm{mM}$ EDTA at $\mathrm{pH}$ 8.0, 0.5\% NP-40) plus protease inhibitor cocktail (Roche), $0.5 \mathrm{mM}$ DTT, and phosphatase inhibitors (sodium orthovanadate, sodium fluoride, $\beta$-glycerophosphate, and mycrocystin-LR) for $15 \mathrm{~min}$ of mixing at $4^{\circ} \mathrm{C}$. Lystes were sonicated briefly to ensure that most chromatin proteins were released. The samples were spun at high speed in a microcentrifuge, supernatants were collected, and protein concentration was quantified using Bradford reagent (Bio-Rad). For immunoprecipitations, $1000 \mu \mathrm{g}$ of total protein was precleared with Protein A/G (Santa Cruz Biotechnology) prior to addition of HA antibody-conjugated beads or TTI1 antisera (followed by addition of Protein A/G beads). For column fractionation, cells were lysed in NETN (without EDTA), and $\sim 40 \mathrm{mg}$ of total protein was loaded onto a 24-mL Superose 6 column. Seven milliliters of void volume was allowed to flow through prior to collecting $480.5-\mathrm{mL}$ fractions. Where indicated, the fractions were used directly for immunoprecipitation (no freeze-thaw).

\section{Plasmids, shRNAs, and siRNAs}

TTI1, TEL2, TTI2 cDNAs are from the hORFeome V5.1 collection, and the Gateway recombination system (Invitrogen) was used to transfer the cDNAs from pDONR-223 to the following vectors: MSCV-IRES-PURO-N-HA-Flag, MSCV-PGK-PURO-CHA-Flag, MSCV-PGK-PURO-N-MYC, MSCV-PGK-PURO-NEGFP, MSCV-CMV-TO-N-HA-Flag-PGK-PURO (inducible). The sequences of shRNAs and siRNAs used in this study are listed in Supplemental Tables S6 and S7, respectively. The shRNA library is in a MSCV-PURO-based vector (MSCV-PM; Open Biosystems nomenclature is pSMP). The shRNAs with the "V3LHS" identifier were subcloned into the MSCV-PM vector from the pGIPZ vector. The shRNAs indicated "CUSTOM" were generated in our laboratory, and the 22-mer shRNA sequence is within the mir30 context and the MSCV-PM vector backbone (the same as the library).

\section{Quantitative RT-PCR}

Total RNA was prepared using the RNAeasy Plus kit (Qiagen), and reverse transcription to generate cDNA was performed using SuperScript III Reverse Transcriptase (\#18080-044, Invitrogen). RT-PCR was done using Platinum Cybergreen Super Mix with 
Rox dye (\#11733-046, Invitrogen) on an Applied Biosystems 7500 Fast PCR machine. The PCR cycling program was done as recommended by the manufacturer. Relative mRNA levels were normalized to expression of human $\beta$-actin. RT-PCR was performed in quadruplicate. Primers used in this study for quantitative RT-PCR are listed in Supplemental Table S8.

\section{Radio-resistant DNA synthesis assay}

Radio-resistant DNA synthesis assays were done as described previously (Silverman et al. 2004). Briefly, U2OS cells were transfected with siRNA, and, $24 \mathrm{~h}$ later, medium containing 10 $\mathrm{nCi} / \mathrm{mL}$ [methyl-14C] thymidine (Amersham) was added, and the cells were incubated for $24 \mathrm{~h}$. After another $24 \mathrm{~h}$ incubation with medium without label, the cells were irradiated with 15 Gy of IR. Following a 30-min incubation, the cells were pulselabeled with $2.5 \mu \mathrm{Ci} / \mathrm{mL}$ [methyl-3H] thymidine (Amersham) for $20 \mathrm{~min}$, and then washed twice with medium containing 2.5 $\mathrm{mM}$ cold thymidine (no serum). Cells were harvested by trypsinization, and TCA precipitation was performed on Whatman glass microfiber filters using a vacuum manifold. Following an ethanol wash, the filters were dried and counted using a liquid scintillation counter (Beckman LS6000). The ratio of ${ }^{3} \mathrm{H}$ counts per minute to ${ }^{14} \mathrm{C}$ counts per minute, corrected for those counts per minute that were the result of channel crossover, was a measure of DNA synthesis.

\section{G2/M checkpoint assay}

U2OS cells were transfected with $50 \mathrm{nM}$ final concentration of siRNA using oligofectamine reagent (Invitrogen) following the manufacturer's recommendations. After 4-6 d to allow for efficient gene knockdown, cells were treated with 10 Gy of IR and incubated for $1 \mathrm{~h}$ at $37^{\circ} \mathrm{C}$. Nocodozole was added to the medium at a final concentration of $400 \mathrm{ug} / \mathrm{mL}$, and cells were incubated for an additional $17 \mathrm{~h}$ at $37^{\circ} \mathrm{C}$. Cells were fixed with ethanol, stained with phospho-S10 Histone $\mathrm{H} 3$ antisera followed by Alexa 488 secondary antibody and propidium iodide, and analyzed by FACS. The percentage of phospho-S10 Histone H3 cells in ATM, ATR, or TTI1 knockdown cells was normalized to FF control knockdown cells to give fold change mitotic index.

\section{$M C A$}

U2OS cells were retrovirally transduced with MSCV-dsRed (no selection marker) and FACS-sorted to obtain a more homogeneous population. The dsRed cells were then infected with retrovirus expressing individual shRNAs of interest, selected with puromycin, and then equally mixed with U2OS cells (uncolored) expressing a control shRNA targeting firefly luciferase. The mixed population was left untreated or treated with 3 Gy of $\gamma$-irradiation, $75-100 \mathrm{nM}$ MMC, $5 \mathrm{nM} \mathrm{CPT,} \mathrm{or} 5 \mathrm{~J} / \mathrm{m} 2 \mathrm{UV}$ light, and, following approximately six population doublings, was harvested for FACS analysis. For a graphical representation, the percent of dsRed-expressing cells in DNA damage-treated samples was normalized to that of untreated cells. We also normalized to the performance of dsRed cells carrying a control shRNA. For MMC- and CPT-treated cells, the medium containing the drug was removed after $12 \mathrm{~h}$ and replaced with fresh medium without drug. For siRNA experiments, U2OS cells were transfected with $50 \mathrm{nM}$ siRNAs using oligofectamine, mixed for $\mathrm{MCA}$, and treated with DNA damage at $72 \mathrm{~h}$ post-transfection.

\section{Acknowledgments}

We thank T. de Lange for the TEL2 antibody; L. Cantley for the PI3K p85 antibody; M. Kastan for the Flag-ATM expression vector; K. Hofmann for advice; M. Schlabach, J. Luo, and Q. Xu for assistance with microarray hybridization and data analysis; $\mathrm{E}$. Bennett, M. Sowa, and A. Elia for assistance with FPLC and mass spectrometry; and A. Smogorzewska, B. Adamson, M. Naylor, A. Burrows, and other Elledge laboratory members for sharing unpublished results, experimental assistance, and many helpful discussions. K.E.H. is a Special Fellow of the Leukemia and Lymphoma Society. C.C.-R. is an EMBO fellow. S.J.E. is an Investigator of the Howard Hughes Medical Institute. This work is supported by grants from the National Institutes of Health and NCI (to S.J.E.)

\section{References}

Ahmed S, Alpi A, Hengartner MO, Gartner A. 2001. C. elegans RAD-5/CLK-2 defines a new DNA damage checkpoint protein. Curr Biol 11: 1934-1944.

Benard C, McCright B, Zhang Y, Felkai S, Lakowski B, Hekimi S. 2001. The C. elegans maternal-effect gene clk-2 is essential for embryonic development, encodes a protein homologous to yeast Tel2p and affects telomere length. Development 128: 4045-4055.

Cimprich KA, Cortez D. 2008. ATR: An essential regulator of genome integrity. Nat Rev Mol Cell Biol 9: 616-627.

Collis SJ, Barber LJ, Clark AJ, Martin JS, Ward JD, Boulton SJ. 2007. HCLK2 is essential for the mammalian S-phase checkpoint and impacts on Chk1 stability. Nat Cell Biol 9: 391-401.

Collis SJ, Ciccia A, Deans AJ, Horejsi Z, Martin JS, Maslen SL, Skehel JM, Elledge SJ, West SC, Boulton SJ. 2008. FANCM and FAAP24 function in ATR-mediated checkpoint signaling independently of the Fanconi anemia core complex. Mol Cell 32: 313-324.

Danielsen JM, Larsen DH, Schou KB, Freire R, Falck J, Bartek J, Lukas J. 2009. HCLK2 is required for activity of the DNA damage response kinase ATR. J Biol Chem 284: 4140-4147.

Giannattasio M, Lazzaro F, Plevani P, Muzi-Falconi M. 2005. The DNA damage checkpoint response requires histone $\mathrm{H} 2 \mathrm{~B}$ ubiquitination by Rad6-Bre1 and H3 methylation by Dot1. J Biol Chem 280: 9879-9886.

Hayashi T, Hatanaka M, Nagao K, Nakaseko Y, Kanoh J, Kokubu A, Ebe M, Yanagida M. 2007. Rapamycin sensitivity of the Schizosaccharomyces pombe tor2 mutant and organization of two highly phosphorylated TOR complexes by specific and common subunits. Genes Cells 12: 1357-1370.

Hekimi S, Boutis P, Lakowski B. 1995. Viable maternal-effect mutations that affect the development of the nematode Caenorhabditis elegans. Genetics 141: 1351-1364.

Hresko RC, Mueckler M. 2005. mTOR.RICTOR is the Ser473 kinase for Akt/protein kinase B in 3T3-L1 adipocytes. I Biol Chem 280: 40406-40416.

Huang J, Gong Z, Ghosal G, Chen J. 2009. SOSS complexes participate in the maintenance of genomic stability. Mol Cell 35: 384-393.

Jiang N, Benard CY, Kebir H, Shoubridge EA, Hekimi S. 2003. Human CLK2 links cell cycle progression, apoptosis, and telomere length regulation. J Biol Chem 278: 21678-21684.

Kaufman PD, Kobayashi R, Stillman B. 1997. Ultraviolet radiation sensitivity and reduction of telomeric silencing in Saccharomyces cerevisiae cells lacking chromatin assembly factor-I. Genes Dev 11: 345-357.

Kota RS, Runge KW. 1999. Tel2p, a regulator of yeast telomeric length in vivo, binds to single-stranded telomeric DNA in vitro. Chromosoma 108: 278-290.

Lakowski B, Hekimi S. 1996. Determination of life-span in Caenorhabditis elegans by four clock genes. Science 272: 1010-1013. 
Hurov et al.

Lavin MF. 2008. Ataxia-telangiectasia: From a rare disorder to a paradigm for cell signalling and cancer. Nat Rev Mol Cell Biol 9: 759-769.

Li Y, Bolderson E, Kumar R, Muniandy PA, Xue Y, Richard DJ, Seidman M, Pandita TK, Khanna KK, Wang W. 2009. HSSB1 and hSSB2 form similar multiprotein complexes that participate in DNA damage response. J Biol Chem 284: 23525-23531.

Lim CS, Mian IS, Dernburg AF, Campisi J. 2001. C. elegans clk-2, a gene that limits life span, encodes a telomere length regulator similar to yeast telomere binding protein Tel2p. Curr Biol 11: 1706-1710.

Linger J, Tyler JK. 2005. The yeast histone chaperone chromatin assembly factor 1 protects against double-strand DNA-damaging agents. Genetics 171: 1513-1522.

Luo J, Emanuele MJ, Li D, Creighton CJ, Schlabach MR, Westbrook TF, Wong KK, Elledge SJ. 2009. A genome-wide RNAi screen identifies multiple synthetic lethal interactions with the Ras oncogene. Cell 137: 835-848.

Lustig AJ, Petes TD. 1986. Identification of yeast mutants with altered telomere structure. Proc Nat1 Acad Sci 83: 1398-1402.

Matsuoka S, Huang M, Elledge SJ. 1998. Linkage of ATM to cell cycle regulation by the Chk2 protein kinase. Science 282: 1893-1897.

Matsuoka S, Ballif BA, Smogorzewska A, McDonald ER III, Hurov KE, Luo J, Bakalarski CE, Zhao Z, Solimini N, Lerenthal Y, et al. 2007. ATM and ATR substrate analysis reveals extensive protein networks responsive to DNA damage. Science 316: 1160-1166.

Mi H, Guo N, Kejariwal A, Thomas PD. 2007. PANTHER version 6: Protein sequence and function evolution data with expanded representation of biological pathways. Nucleic Acids Res 35: D247-D252. doi: 10.1093/nar/gk1869.

Paddison PJ, Silva JM, Conklin DS, Schlabach M, Li M, Aruleba S, Balija V, O'Shaughnessy A, Gnoj L, Scobie K, et al. 2004. A resource for large-scale RNA-interference-based screens in mammals. Nature 428: 427-431.

Paulsen RD, Soni DV, Wollman R, Hahn AT, Yee MC, Guan A, Hesley JA, Miller SC, Cromwell EF, Solow-Cordero DE, et al. 2009. A genome-wide siRNA screen reveals diverse cellular processes and pathways that mediate genome stability. Mol Cell 35: 228-239.

Runge KW, Zakian VA. 1996. TEL2, an essential gene required for telomere length regulation and telomere position effect in Saccharomyces cerevisiae. Mol Cell Biol 16: 3094-3105.

Sarbassov DD, Guertin DA, Ali SM, Sabatini DM. 2005 Phosphorylation and regulation of $\mathrm{Akt} / \mathrm{PKB}$ by the rictormTOR complex. Science 307: 1098-1101.

Schlabach MR, Luo J, Solimini NL, Hu G, Xu Q, Li MZ, Zhao Z, Smogorzewska A, Sowa ME, Ang XL, et al. 2008. Cancer proliferation gene discovery through functional genomics. Science 319: 620-624.

Shikata M, Ishikawa F, Kanoh J. 2007. Tel2 is required for activation of the Mrcl-mediated replication checkpoint. I Biol Chem 282: 5346-5355.

Silva JM, Li MZ, Chang K, Ge W, Golding MC, Rickles RJ, Siolas D, Hu G, Paddison PJ, Schlabach MR, et al. 2005. Secondgeneration shRNA libraries covering the mouse and human genomes. Nat Genet 37: 1281-1288.

Silva JM, Marran K, Parker JS, Silva J, Golding M, Schlabach MR, Elledge SJ, Hannon GJ, Chang K. 2008. Profiling essential genes in human mammary cells by multiplex RNAi screening. Science 319: 617-620.

Silverman J, Takai H, Buonomo SB, Eisenhaber F, de Lange T. 2004. Human Rif1, ortholog of a yeast telomeric protein, is regulated by ATM and 53BP1 and functions in the S-phase checkpoint. Genes Dev 18: 2108-2119.
Skaar JR, Richard DJ, Saraf A, Toschi A, Bolderson E, Florens L, Washburn MP, Khanna KK, Pagano M. 2009. INTS3 controls the hSSB1-mediated DNA damage response. J Cell Biol 187: 25-32.

Smogorzewska A, Matsuoka S, Vinciguerra P, McDonald ER 3rd, Hurov KE, Luo J, Ballif BA, Gygi SP, Hofmann K, D'Andrea $\mathrm{AD}$, et al. 2007. Identification of the FANCI protein, a monoubiquitinated FANCD2 paralog required for DNA repair. Cell 129: 289-301.

Stepanova L, Leng X, Parker SB, Harper JW. 1996. Mammalian p50Cdc37 is a protein kinase-targeting subunit of Hsp90 that binds and stabilizes Cdk4. Genes Dev 10: 1491-1502.

Stokes MP, Rush J, Macneill J, Ren JM, Sprott K, Nardone J, Yang V, Beausoleil SA, Gygi SP, Livingstone M, et al. 2007. Profiling of UV-induced ATM/ATR signaling pathways. Proc Natl Acad Sci 104: 19855-19860.

Takai H, Wang RC, Takai KK, Yang H, de Lange T. 2007. Tel2 regulates the stability of PI3K-related protein kinases. Cell 131: $1248-1259$.

Thomas PD, Campbell MJ, Kejariwal A, Mi H, Karlak B, Daverman R, Diemer K, Muruganujan A, Narechania A. 2003. PANTHER: A library of protein families and subfamilies indexed by function. Genome Res 13: 2129-2141.

Tonkin ET, Wang TJ, Lisgo S, Bamshad MJ, Strachan T. 2004. NIPBL, encoding a homolog of fungal Scc2-type sister chromatid cohesion proteins and fly Nipped-B, is mutated in Cornelia de Lange syndrome. Nat Genet 36: 636-641.

Wang B, Hurov K, Hofmann K, Elledge SJ. 2009. NBA1, a new player in the Brcal A complex, is required for DNA damage resistance and checkpoint control. Genes Dev 23: 729-739. 


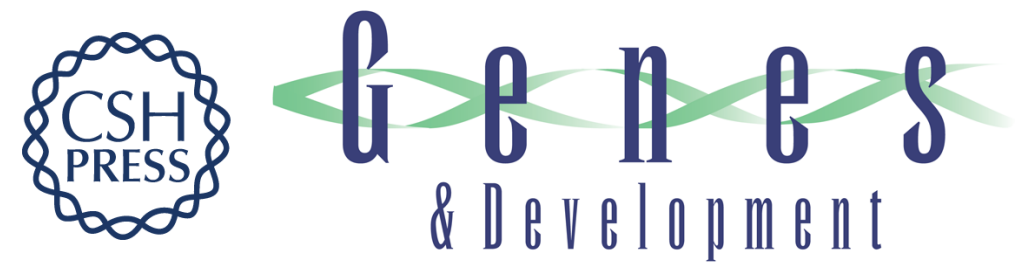

\section{A genetic screen identifies the Triple T complex required for DNA damage signaling and ATM and ATR stability}

Kristen E. Hurov, Cecilia Cotta-Ramusino and Stephen J. Elledge

Genes Dev. 2010, 24:

Access the most recent version at doi:10.1101/gad.1934210

Supplemental http://genesdev.cshlp.org/content/suppl/2010/08/30/24.17.1939.DC1
Material

References This article cites 41 articles, 22 of which can be accessed free at:

http://genesdev.cshlp.org/content/24/17/1939.full.html\#ref-list-1

License

Email Alerting

Receive free email alerts when new articles cite this article - sign up in the box at the top

Service

right corner of the article or click here.

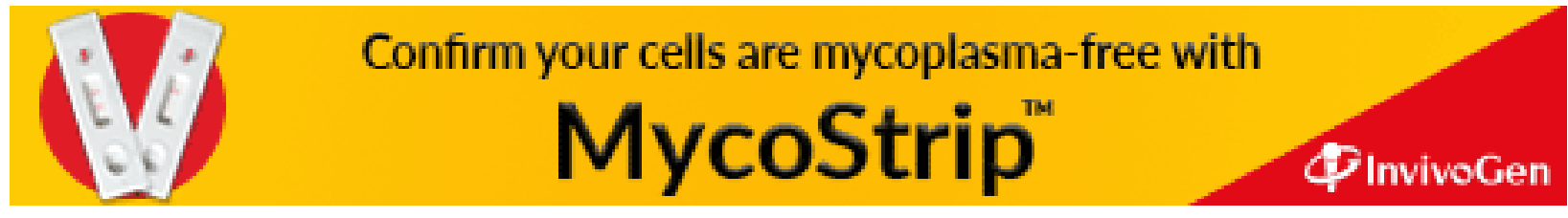

